\title{
Self-interactions of two monoclonal antibodies: small-angle $X$-ray scattering, light scattering and coarse-grained modeling
}

\author{
Sujata Mahapatra ${ }^{\mathrm{a}, \mathrm{b}, \$, *}$, Marco Polimenic* ${ }^{*}$, Lorenzo Gentiluomo $^{\mathrm{d}, \mathrm{e}, \S}$, Dierk Roessner ${ }^{\mathrm{d}}$, Wolfgang \\ Frieß $^{\mathrm{e}}$, Günther H.J. Peters ${ }^{\mathrm{b}}$, Werner W. Streicher ${ }^{\mathrm{a}, \&}$, Mikael Lund ${ }^{\mathrm{c}}$, Pernille Harris ${ }^{\mathrm{b}, \#}$ \\ aNovozymes A/S, Biologiens Vej 2, 2800 Kgs. Lyngby, Denmark \\ bDepartment of Chemistry, Technical University of Denmark, Kemitorvet, Building 207, 2800 Kgs. Lyngby, Denmark \\ ${ }^{c}$ Division of Theoretical Chemistry, Department of Chemistry, Lund University, Naturvetarvägen 14, 22362 Lund, \\ Sweden \\ ${ }^{\mathrm{d}}$ Wyatt Technology Europe GmbH, Hochstrasse 12a, 56307 Dernbach, Germany \\ eLudwig Maximilians-Universität München, Department of Pharmacy, Pharmaceutical Technology and \\ Biopharmaceutics, Butenandtstrasse 5, 81377 Munich, Germany \\ \$Present address: Department of Molecular Biology and Genetics, Aarhus University, Denmark \\ ${ }^{\S}$ Present address: Coriolis Pharma, Fraunhoferstraße 18B, 82152 Munich, Germany \\ \&Present address: NanoTemper Technologies GmbH, Floessergasse 4, 81369 Muenchen \\ \#Present address: Department of Chemistry, University of Copenhagen, Universitetsparken 5, 2100 Copenhagen \\ *These authors contributed equally to this work as first authors.
}

\section{Supporting Information}

\section{Static Light Scattering theory}

Static light scattering (SLS) is used to observe the protein solution properties ${ }^{54}$ and measure interactions in terms of second virial coefficients, $B_{22}$. In the limit of small scattering angles the excess Rayleigh ratio, $\bar{R}_{\theta}$, is related to the osmotic pressure, $\Pi$, through the relation ${ }^{55}$ :

$$
\frac{K c\left(\partial n / \partial c_{p}\right)^{2}}{\bar{R}_{\theta}}=\frac{1}{R T}\left(\frac{\partial \Pi}{\partial c_{p}}\right)
$$

Here $K$ is the optical constant which is equal to $2 \pi^{2} n_{0}^{2} /\left(N_{\mathrm{A}} \lambda^{4}\right)$, where $n_{0}$ is the refractive index of the solvent and $N_{A}$ is Avogadro's number and $\lambda$ is the wavelength of the incident radiation; $c_{p}$ is protein concentration; $\partial n / \partial c_{p}$ is the refractive index increment of the protein solution; $R$ is the gas constant and $T$ is the absolute temperature.

Using the virial expansion,

$$
\frac{\Pi}{R T}=\frac{c_{p}}{M_{w}}+B_{22} c_{p}^{2}+\cdots \text { higher order terms }
$$

Equation (A1) transforms as: 


$$
\frac{K c\left(\partial n / \partial c_{p}\right)^{2}}{\bar{R}_{\theta}}=\frac{1}{M_{\mathrm{w}}}+2 B_{22} c_{p}
$$

where $M_{\mathrm{w}}$ is the protein molecular weight and the $B_{22}$ is calculated from a linear fit of equation (A2).

\section{Small-angle X-ray scattering theory}

Small-angle X-ray scattering (SAXS) is used to study the structural properties and interactions of biological molecules in solutions ${ }^{56}$. Due to the random orientations of the molecules in the solution, SAXS intensities represent an average over all the orientations.

The momentum transfer vector $q^{56}$ is defined as:

$$
q=\frac{4 \pi \sin \theta}{\lambda}
$$

where $\lambda$ is the wavelength and $2 \theta$ is the scattering angle. The total scattering intensity, $I(q)$, is

$$
I(q) \propto P(q) \cdot S(q)
$$

where $P(q)$ is the form factor which represents the average overall sizes and orientations of the scattering particle, and the effective structure factor, $S(q)$, describes the inter-particle interaction present in the solution, such as repulsion and attraction. At infinite dilution, $S(q)=$ 1 and no inter-particle interactions are present ${ }^{57}$. We obtained $P(q)$ by merging the low and high concentration data of each sample. Further, the effective structure factor, $S(q)$, at a given concentration was found by dividing $I(q)$ by $P(q)$.

\section{Sequence alignment}

Differences, Gaps

Table S1 Heavy chain alignment of PPI03 and PPI13.

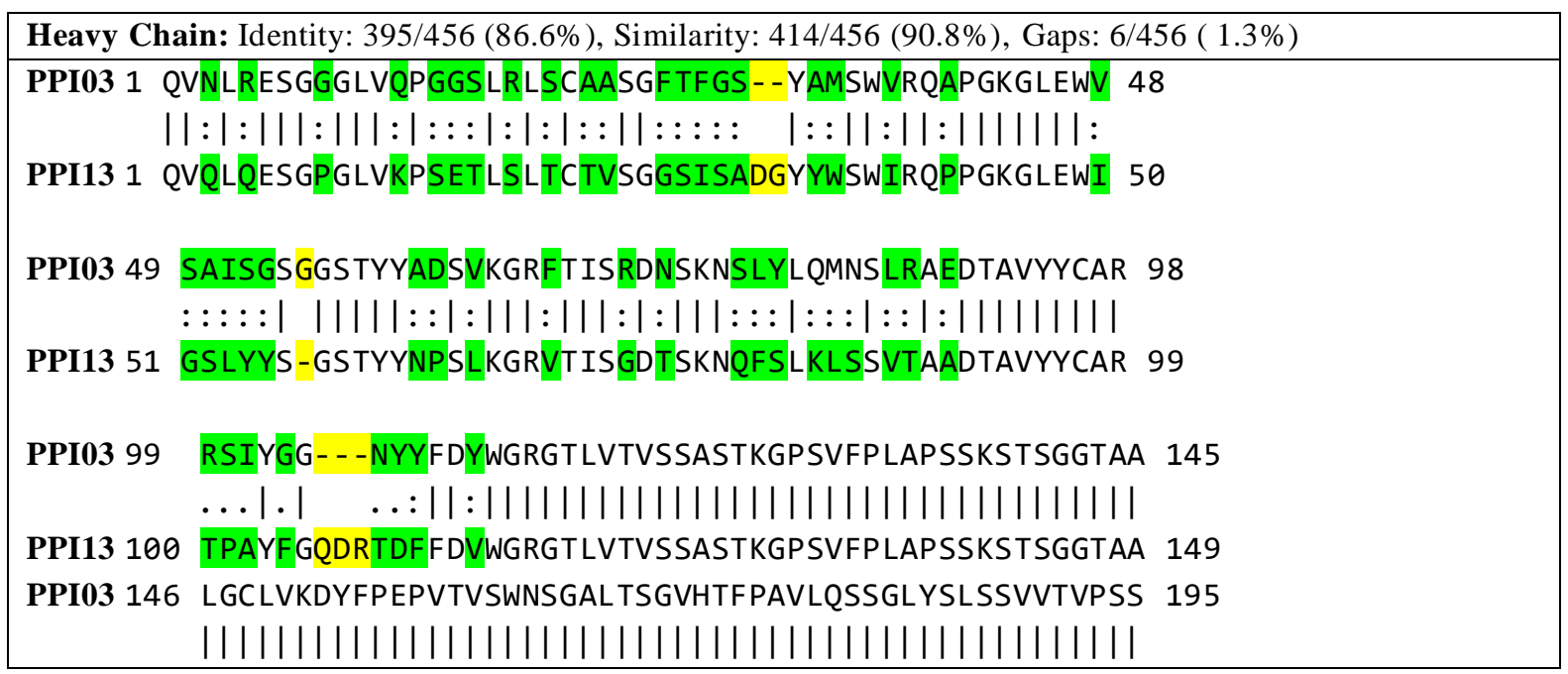




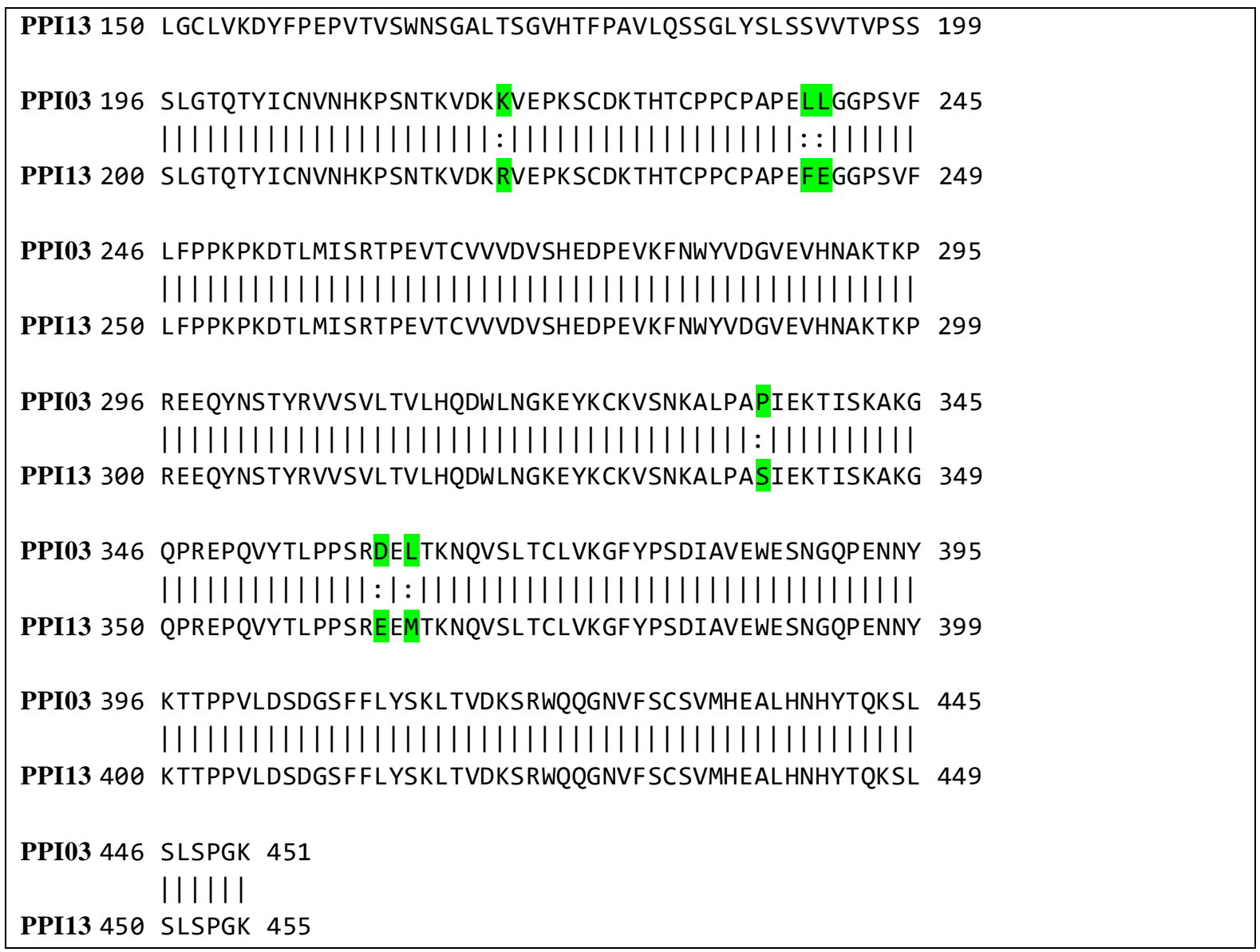

Table S2 Light chain alignment of PPI03 and PPI13.

\begin{tabular}{|c|}
\hline Light Chain: Identity: 197/214 (92.1\%), Similarity: 207/214 (96.7\%), Gaps: 0/214 ( 0.0\%) \\
\hline 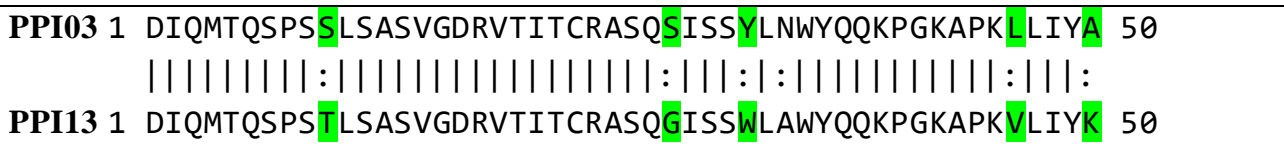 \\
\hline 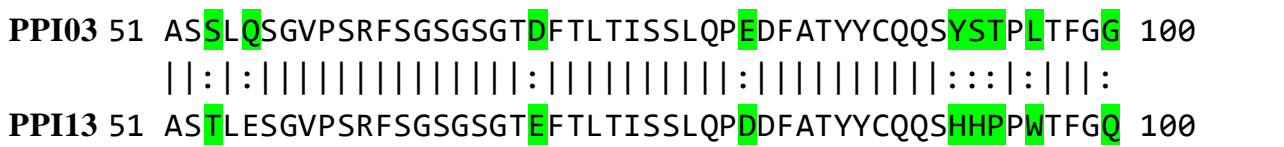 \\
\hline 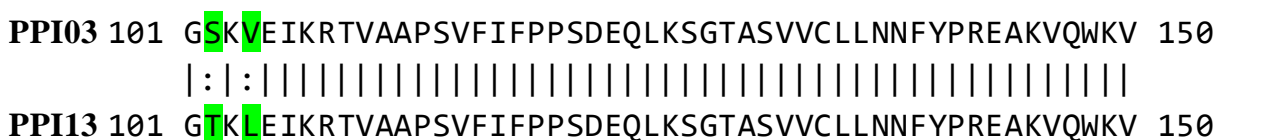 \\
\hline $\begin{array}{l}\text { PPI03 } 151 \text { DNALQSGNSQESVTEQDSKDSTYSLSSTLTLSKADYEKHKVYACEVTHQG } 200 \\
\text { ||||||||||||||||||||||||||||||||||||||||||||||||||||||||||||||||| }\end{array}$ \\
\hline PPI13 151 DNALQSGNSQESVTEQDSKDSTYSLSSTLTLSKADYEKHKVYACEVTHQG 200 \\
\hline $\begin{aligned} \text { PPI03 } 201 & \text { LSSPVTKSFNRGEC } 214 \\
& \|\|\||\||\||\|||| \\
\text { PPI13 } 201 & \text { LSSPVTKSFNRGEC } 214\end{aligned}$ \\
\hline
\end{tabular}


Table S3 Experimental set up of SAXS measurements.

\begin{tabular}{|l|l|}
\hline Instrument & BM29, ESRF \\
\hline Wavelength $(\AA)$ & 0.99 \\
\hline q-range $\left(\AA^{-1}\right)$ & $0.004-0.49$ \\
\hline Sample-to-detector distance $(\mathrm{m})$ & 2.864 \\
\hline Detector & PILATUS 1M \\
\hline Exposure time $(\mathrm{s})$ & $10 \times 1.00$ \\
\hline Beam size $\left(\mu m^{2}\right)$ & $700 \times 700$ \\
\hline Sample configuration & 1.8 mm quartz glass capillary \\
\hline Absolute scaling method & Comparison to water in sample capillary \\
\hline Normalization & To transmitted intensity by beam-stop counter \\
\hline Monitoring for radiation damage & $\begin{array}{l}\text { Control of un-subtracted and scaled subtracted data for } \\
\text { systematic changes typical for radiation damage }\end{array}$ \\
\hline
\end{tabular}

Table S4 Samples for SAXS and SLS experiments performed at varying protein concentrations.

\begin{tabular}{|c|c|c|c|c|}
\hline Protein & Buffer & Additive & $\begin{array}{l}\text { SAXS } \\
\text { measured } \\
\text { concentrations } \\
(\mathrm{g} / \mathrm{L})\end{array}$ & $\begin{array}{l}\text { SLS measured } \\
\text { concentrations } \\
(\mathrm{g} / \mathrm{L})\end{array}$ \\
\hline \multirow{2}{*}{$\begin{array}{l}\text { PPI03 } \\
\text { (Human } \\
\text { IgG1к) }\end{array}$} & \multirow{2}{*}{$\begin{array}{l}10 \mathrm{mM} \text { histidine } \\
\mathrm{pH} 6.0\end{array}$} & - & \multirow[t]{2}{*}{$0.5-130$} & \multirow[t]{2}{*}{$1-10$} \\
\hline & & $\begin{array}{l}\mathrm{NaCl}(35,70 \text { and } \\
140 \mathrm{mM})\end{array}$ & & \\
\hline \multirow{2}{*}{ 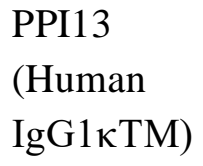 } & \multirow{2}{*}{$\begin{array}{l}10 \mathrm{mM} \text { histidine } \\
\text { pH } 6.0\end{array}$} & - & \multirow[t]{2}{*}{$0.5-120$} & \multirow[t]{2}{*}{$1-10$} \\
\hline & & $\begin{array}{l}\mathrm{NaCl}(35,70 \text { and } \\
140 \mathrm{mM})\end{array}$ & & \\
\hline
\end{tabular}



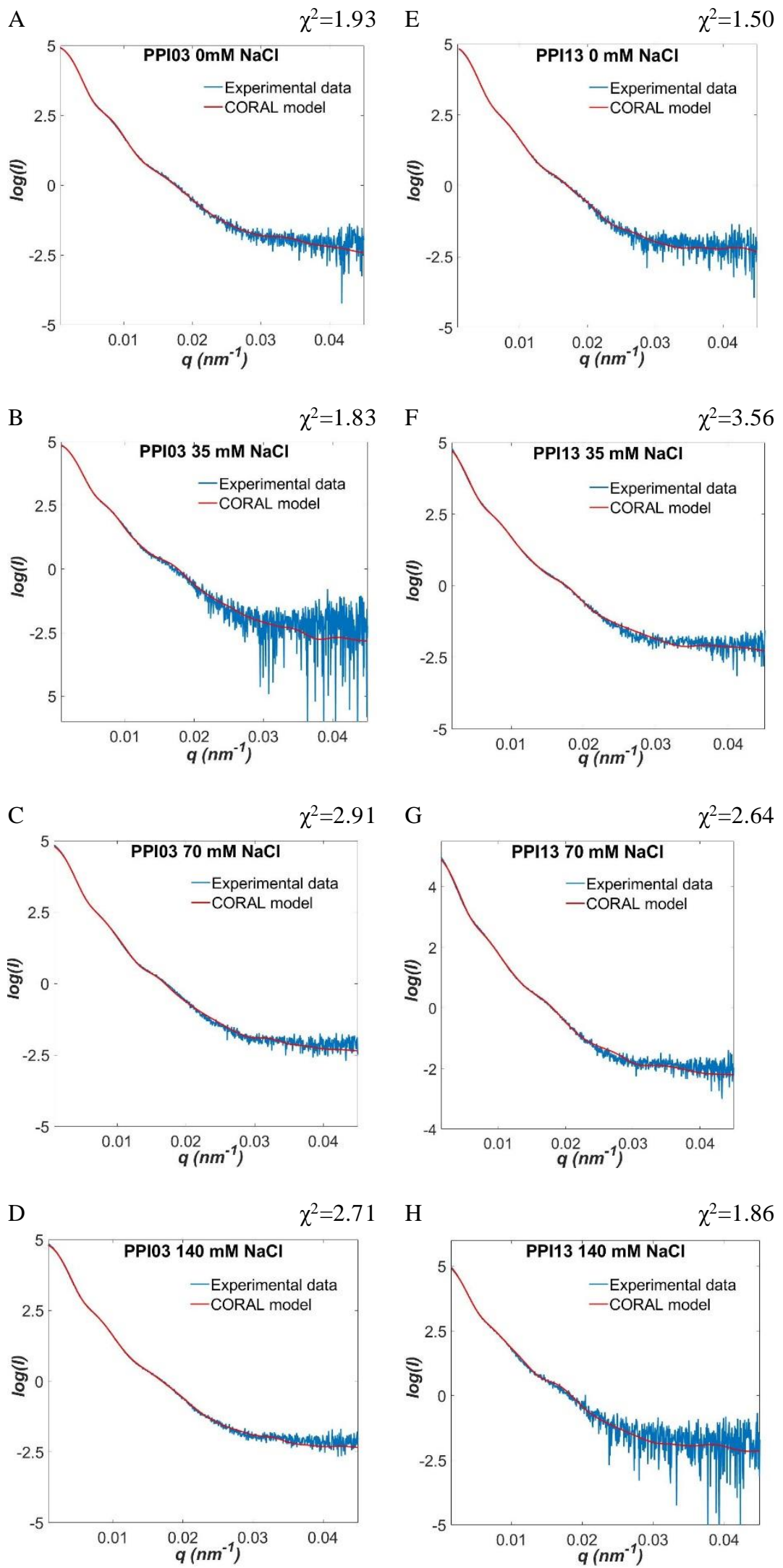

Figure S1 CORAL fits to experimental data. PPI03 and PPI13 in (A, E)10 mM histidine, 0 $\mathrm{mM} \mathrm{NaCl},(\mathrm{B}, \mathrm{F}) 10 \mathrm{mM}$ histidine, $35 \mathrm{mM} \mathrm{NaCl},(\mathrm{C}, \mathrm{G}) 10 \mathrm{mM}$ histidine, $70 \mathrm{mM} \mathrm{NaCl}$ and (D,F) $10 \mathrm{mM}$ histidine, $140 \mathrm{mM} \mathrm{NaCl}$. 


\section{(A) PPI03}

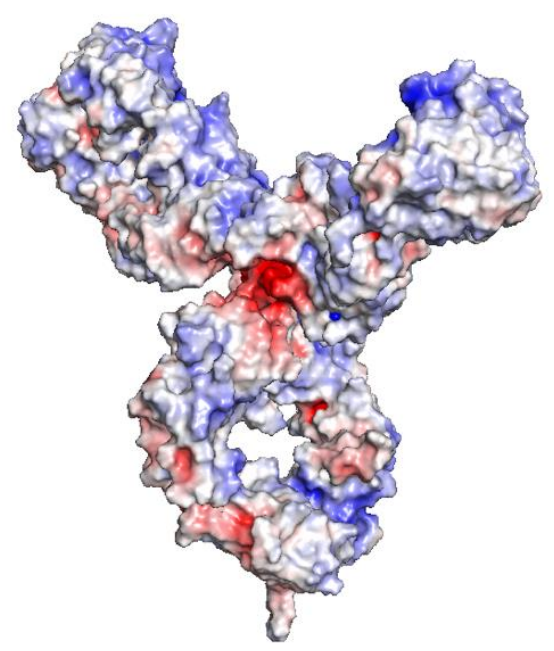

(B) PPI13

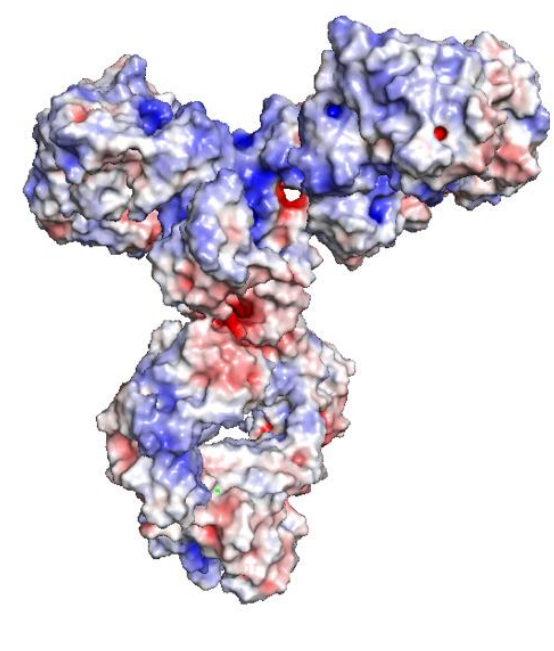

\section{-5.000
-5.000}

Figure S2 Surface electrostatics representation of SAXS derived structures for (A) PPI03 and (B) PPI13 using APBS tools in PyMOL, 180 degree rotation of the mAbs side shown in of Figure 7. 


\section{Simulations}

Table S5 $M_{W}$ and $\sigma_{i i}$ for amino acids and $\mathrm{N}$ and $\mathrm{C}$ terminals used in the simulations.

\begin{tabular}{|c|c|c|c|}
\hline Amino Acid & Abbreviation & $M_{w}(k D a)$ & $\sigma_{i i}(\AA)$ \\
\hline C- terminal & CTR & 16 & 3.1 \\
\hline $\mathrm{N}$-terminal & NTR & 14 & 3.0 \\
\hline Alanine & ALA & 66 & 5.0 \\
\hline Isoleucine & ILE & 102 & 5.8 \\
\hline Leucine & LEU & 102 & 5.1 \\
\hline Methionine & MET & 122 & 6.2 \\
\hline Phenylaniline & PHE & 138 & 6.4 \\
\hline Valine & VAL & 90 & 5.6 \\
\hline Proline & PRO & 90 & 5.6 \\
\hline Arginine & $\mathrm{ARG}$ & 144 & 6.5 \\
\hline Lysine & LYS & 116 & 6.1 \\
\hline Aspartic Acid & ASP & 110 & 5.9 \\
\hline Glutamic Acid & GLU & 122 & 6.2 \\
\hline Glutamine & GLN & 120 & 6.1 \\
\hline Asparagine & ASN & 108 & 5.9 \\
\hline Histidine & HIS & 130 & 6.3 \\
\hline Serine & SER & 82 & 5.4 \\
\hline Threonine & THR & 94 & 5.6 \\
\hline Tyrosine & TYR & 154 & 6.7 \\
\hline Cysteine & CYS & 103 & 5.8 \\
\hline Tryptophan & TRP & 176 & 7.0 \\
\hline Glycine & GLY & 54 & 4.7 \\
\hline
\end{tabular}




\section{Salt Parametrization}

We performed Metropolis Monte Carlo (MC) simulations with explicit grand canonical salt insertion for different salt species. Varying the Lennard-Jones radius, $\sigma_{i j}$, and maintaining all the other parameters fixed in Equation 5, we found the radii matching the experimental activity coefficients. Only the first two terms of equation 1 are used for these simulations and the Debye length was set to infinity. $\sigma_{i j}$ for $\mathrm{NaAc}, \mathrm{NH}_{4} \mathrm{Cl}$, and $\mathrm{GndCl}$, have been used as proxy for interactions between $\mathrm{Na}^{+}$and $\mathrm{Cl}^{-}$ions and specific amino acids (see Table S6).

Table S6 Ionic radii matching the experimental activity coefficient for $\mathrm{NaCl}$ and other salt species .

\begin{tabular}{|l|l|l|}
\hline Salt & $\boldsymbol{\sigma}_{\boldsymbol{i i}}(\stackrel{\AA}{\mathbf{A})}$ & Proxy for \\
\hline $\mathrm{NaCl}$ & 4.6 & \\
\hline $\mathrm{NaAc}$ & 5.25 & $\mathrm{Na}^{+} \leftrightarrow \mathrm{Asp} / \mathrm{Glu} / \mathrm{CTR}$ \\
\hline $\mathrm{NH}_{4} \mathrm{Cl}$ & 4.7 & $\mathrm{Lys} \leftrightarrow \mathrm{Cl}^{-}$ \\
\hline $\mathrm{GndCl}$ & 3.5 & $\mathrm{Arg} \leftrightarrow \mathrm{Cl}^{-}$ \\
\hline
\end{tabular}

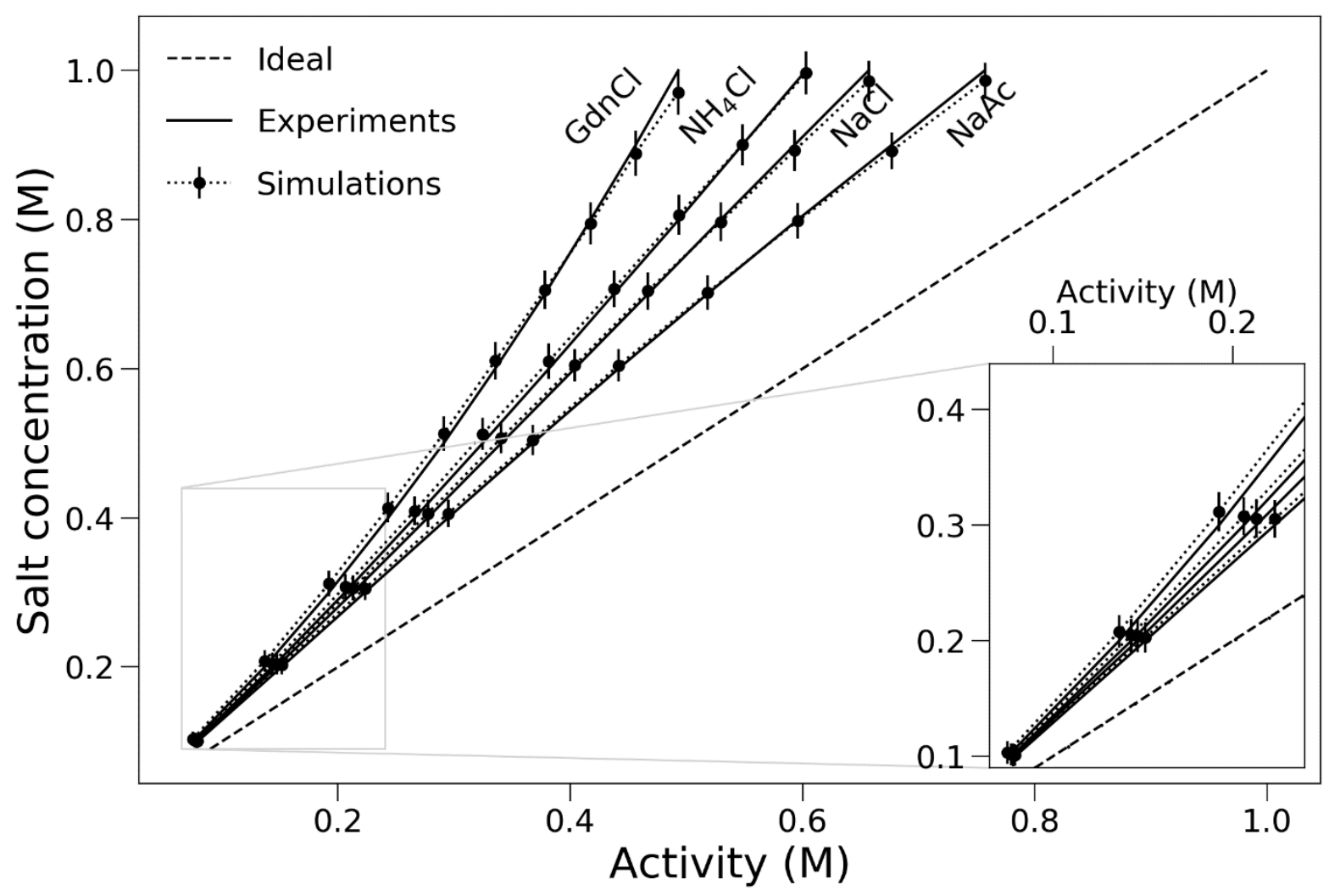

Figure S3 Simulated and experimental activity coefficients for different salt concentrations. The experimental data are used to fit the Lennard-Jones parameters for salts and amino-acid ion interactions. 
A

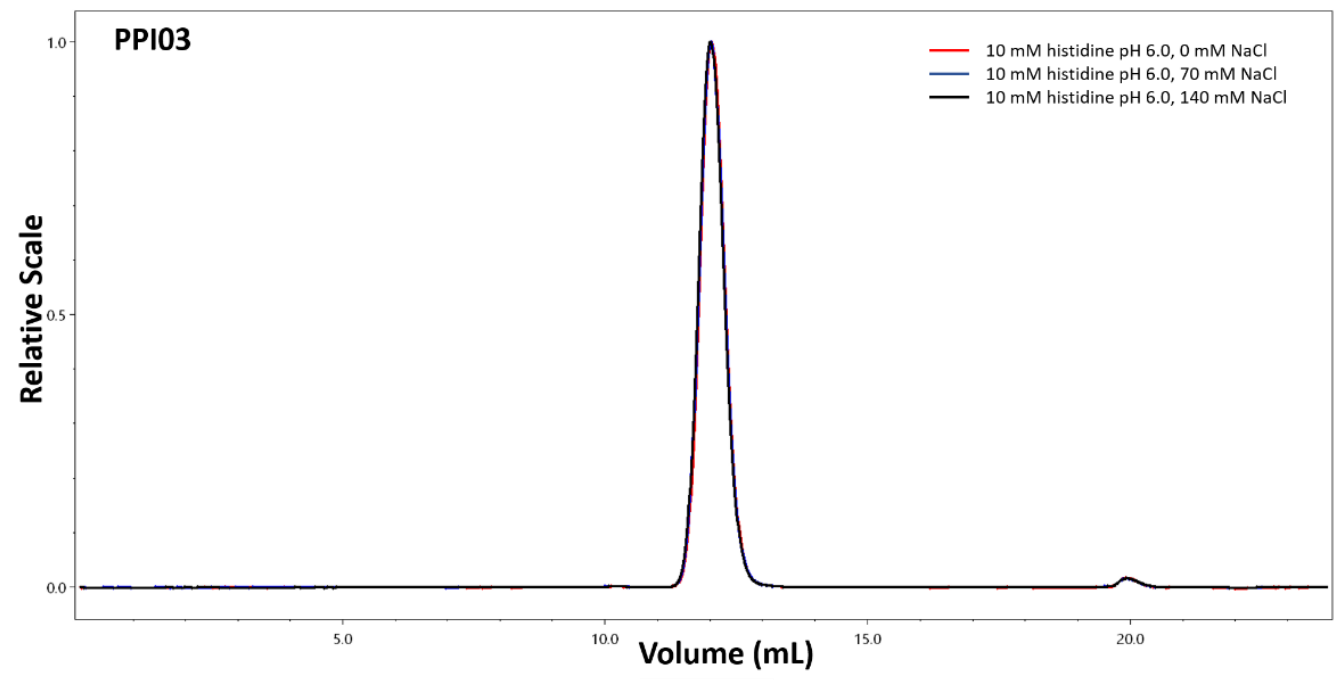

B

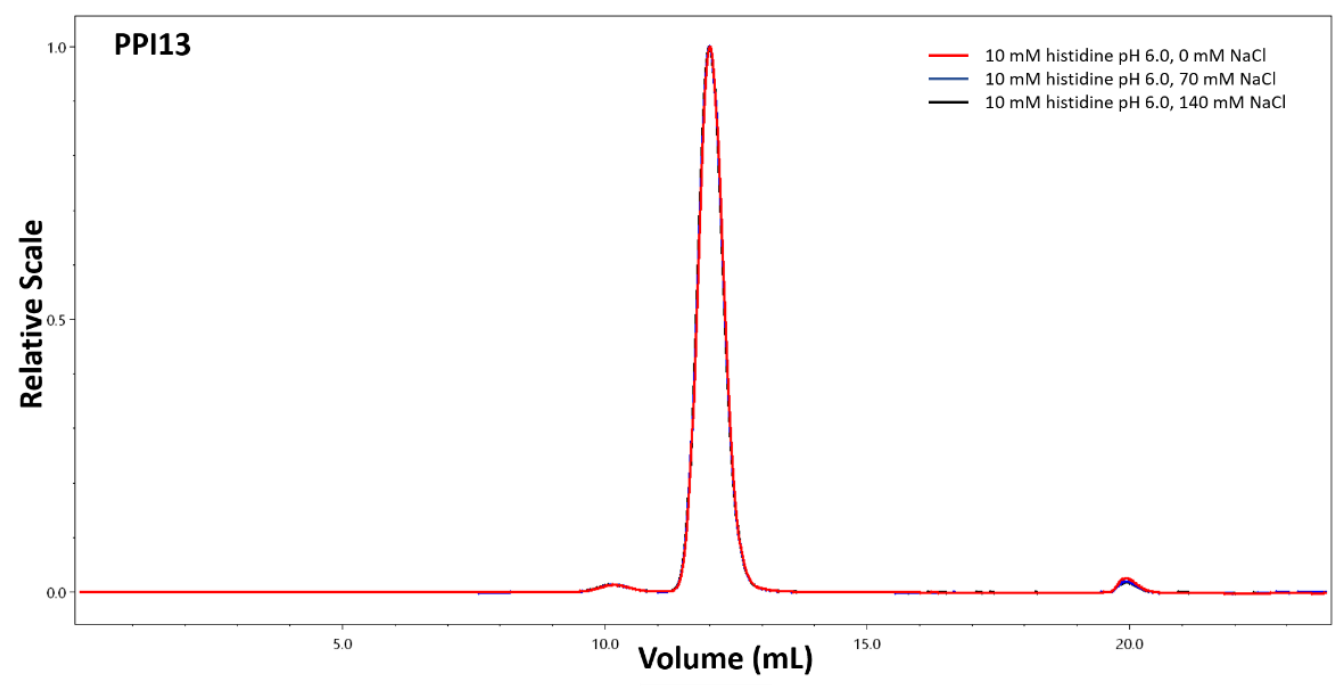


C

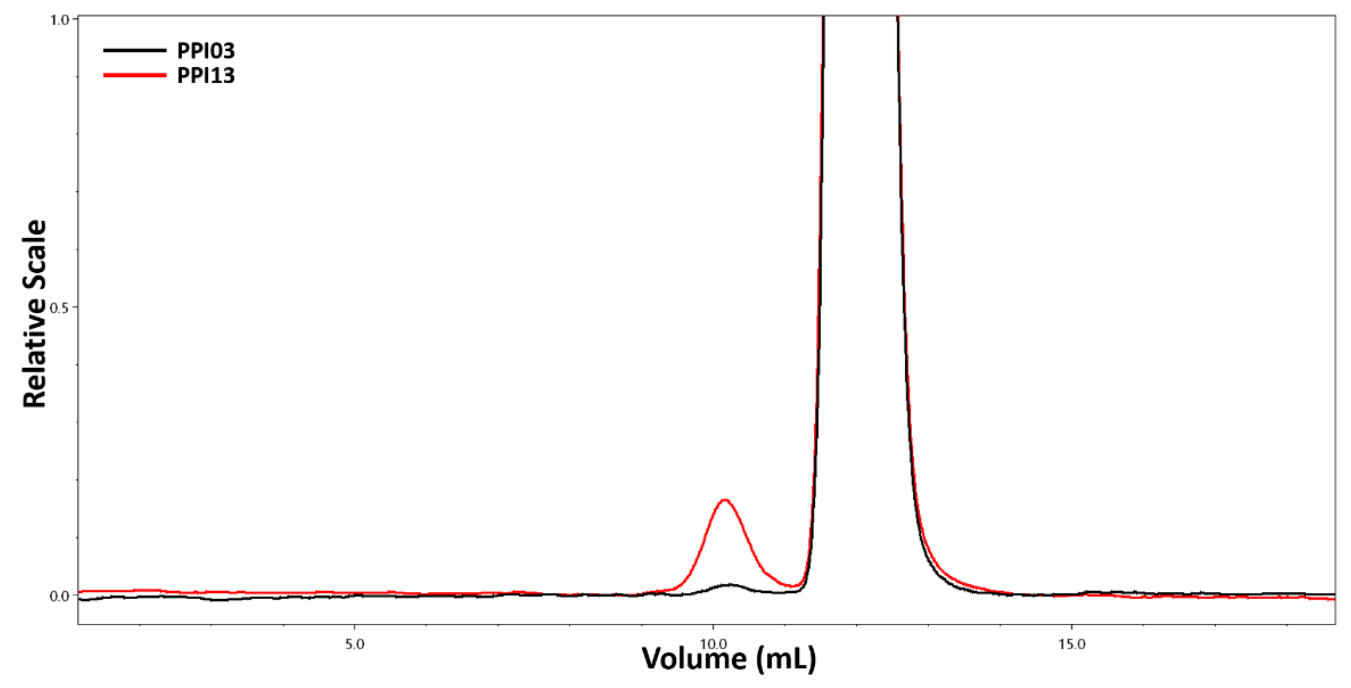

Figure S4 Chromatograms from SEC-MALS at $10 \mathrm{mM}$ histidine pH 6.0 and, $0 \mathrm{mM} \mathrm{NaCl}$ (red); $70 \mathrm{mM} \mathrm{NaCl}$ (blue); $140 \mathrm{mM} \mathrm{NaCl}$ (black) for (A) PPI03 and (B) PPI13. Panel C for zoomed comparison of PPI03 and PPI13 at $10 \mathrm{mM}$ histidine $\mathrm{pH} 6.0$ and $140 \mathrm{mM} \mathrm{NaCL}$.

A

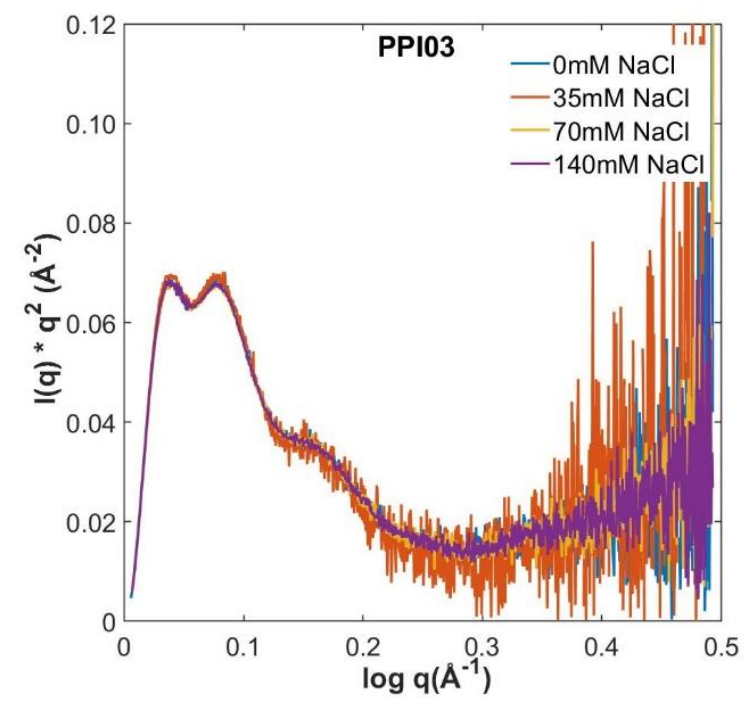

B

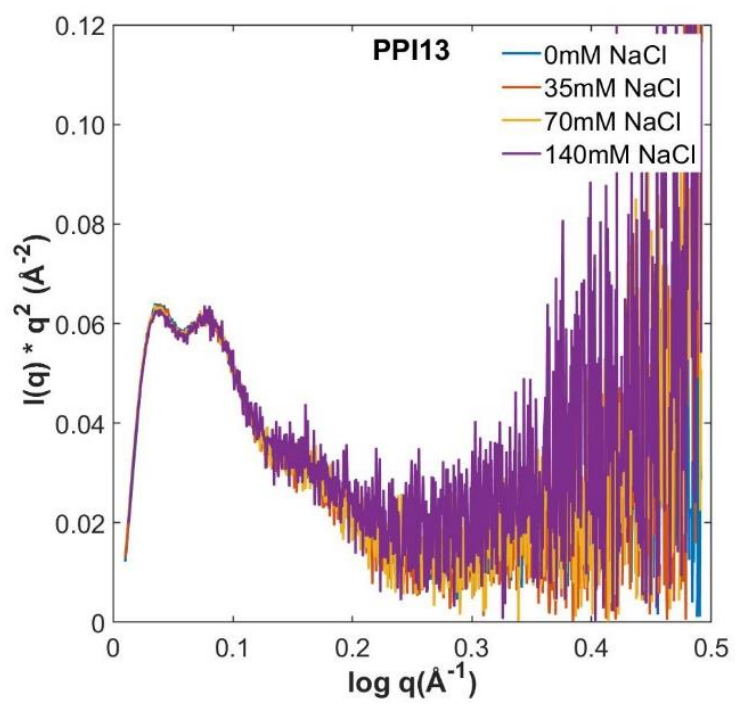

Figure S5 Kratky plots of the scattering profiles that has been used to perform CORAL model. 